\title{
Experimental Decay of Soft Tissues
}

Link to publication record in Manchester Research Explorer

\section{Citation for published version (APA):}

Sansom, R. S., Laflamme, M. (Ed.), Schiffbauer, J. D. (Ed.), \& Darroh, S. A. F. (Ed.) (2014). Experimental Decay of Soft Tissues. In Reading and Writing of the Fossil Record: Preservational Pathways to Exceptional Fossilization: The Paleontological Society Papers, Volume 20 (Vol. PS20, pp. 259-274). Paleontological Research Institution.

\section{Published in:}

Reading and Writing of the Fossil Record: Preservational Pathways to Exceptional Fossilization

\section{Citing this paper}

Please note that where the full-text provided on Manchester Research Explorer is the Author Accepted Manuscript or Proof version this may differ from the final Published version. If citing, it is advised that you check and use the publisher's definitive version.

\section{General rights}

Copyright and moral rights for the publications made accessible in the Research Explorer are retained by the authors and/or other copyright owners and it is a condition of accessing publications that users recognise and abide by the legal requirements associated with these rights.

\section{Takedown policy}

If you believe that this document breaches copyright please refer to the University of Manchester's Takedown Procedures [http://man.ac.uk/04Y6Bo] or contact uml.scholarlycommunications@manchester.ac.uk providing relevant details, so we can investigate your claim.

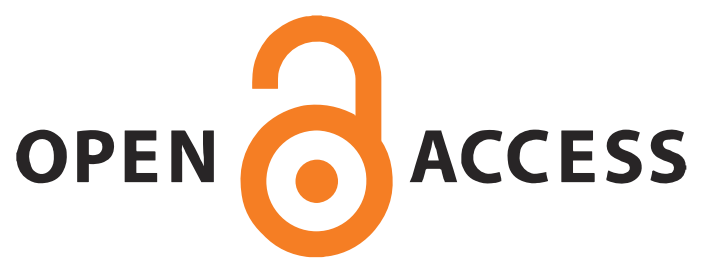




\title{
EXPERIMENTAL DECAY OF SOFT TISSUES
}

\author{
ROBERT S. SANSOM \\ Faculty of Life Sciences, University of Manchester, Oxford Road, Manchester, M13 9PT, UK \\ <robert.sansom@manchester.ac.uk>
}

\begin{abstract}
The exceptionally preserved fossil record of soft tissues sheds light on a wide range of evolutionary episodes from across geological history. Understanding how soft tissues become hard fossils is not a trivial process. A powerful tool in this context is experimentally derived decay data. By studying decay in a laboratory setting and on a laboratory timescale, an understanding of the processes and patterns underlying soft-tissue preservation can be achieved. The considerations and problems particular to experimental decay are explored here in terms of experimental aims, design, variables, and utility. Aims in this context can relate to either reconstruction of the processes of soft-tissue preservation, or to elucidation of the patterns of morphological transformation and data loss occurring during decay. Experimental design is discussed in terms of hypotheses and relevant variables: i.e., the subject organism being decayed (phylogeny, ontogeny, and history), the environment of decay (biological, chemical, and physical) and the outputs (how to measure decay). Variables and practical considerations are illustrated with reference to previous experiments. The principles behind application of experimentally derived decay data to the fossil record are illustrated with three case studies: the interpretation of fossil color, feasibility of fossil embryos, and phylogenetic bias in chordate preservation. A rich array of possibilities for further decay experiments exists and it is hoped that the methodologies outlined herein will provide guidance and a conceptual framework for future studies.
\end{abstract}

\section{INTRODUCTION}

Fossils are old. At first, it would seem that they are so old that researchers would have no hope of experimentally investigating the patterns and processes of fossilization. After all, research proposals for projects on the scale of millions of years are unlikely to be awarded funding. Fossilization, however, is not a linear process with respect to time. The majority of anatomical change and loss occurs in the early stages in the formation of a fossil, after which little change generally takes place. These early stages can be experimentally investigated on a laboratory timescale ranging from hours to months. This is especially relevant to the exceptionally preserved soft-tissue fossil record. Non-biomineralized tissues such as cuticle, muscles, and nerves are lost to decay relatively quickly following death and as such, the soft anatomy of an organism is locked in a post-mortem race between decay and fossilization (Briggs, 1995). In those rare instances that preservation wins, the spectacular fossils that result shed unique and powerful light on a wide range of evolutionary events ranging from the Cambrian explosion of animal life to the origin of bird flight in dinosaurs (Briggs et al., 1994). Soft tissues, however, are extremely labile. They are never preserved as an accurate facsimile of the original organism's in-vivo anatomy in the way that skeletons can be; instead, they have been distorted and changed by the processes of decay and loss that are intrinsic to their fossilization. To make sense of exceptionally preserved fossil soft tissues, we need an understanding of the processes that led to their formation and how the data they provide might have been transformed by their formation. In fact, it is difficult to interpret this class of fossils without experimentally derived data. This review will discuss how experimental taphonomy aims to unlock both the processes and patterns of decay, i.e., the processes that make it possible for soft tissues to become part of the fossil record and the patterns of data loss and transformation that can occur during fossilization. The nature of experimental design and the multitudinous variables involved in taphonomic experiments are also addressed. Finally, examples are used to illustrate how the findings of taphonomic experiments can be applied to paleontological data, and in some instances, transform our interpretation of fossils. 


\section{AIMS: PATTERN AND PROCESS}

All experiments, taphonomic or otherwise, require a clear understanding of how their design and results will address the aim of the experiment. The aims of experimental taphonomy can be loosely classified as relating to either the processes or the patterns of decay and fossilization, both described below. Questions of process concern the mechanisms by which soft tissues are preserved and become part of the fossil record. Questions of pattern aim to identify the sequences of loss and transformation of tissues and morphology that occur during decay.

With respect to processes, two main pathways have been described for the mechanisms of preservation: organic preservation and authigenic microbially mediated preservation (Briggs, 2003). Organic preservation occurs when decay has been sufficiently retarded to allow the original organic biomolecules of the organism (e.g., macromolecules, lipids, proteins) to be preserved (Briggs et al., 2000; Briggs, 2003). This kind of preservation can be enhanced by particular kinds of subsequent diagenesis (Butterfield, 2003; Page et al., 2008). Biomolecules will be transformed during the fossilization process, and this transformation can be investigated experimentally. For example, maturation experiments demonstrate fossil arthropod cuticle is more similar in terms of aliphatic composition to decayed or matured arthropod chitin than to fresh chitin (Gupta et al., 2006; Gupta and Summons, 2011). Because organic preservation essentially requires retardation of decay, it can be experimentally investigated through identification and/or manipulation of the factors that affect rates of tissue decomposition. Anaerobic conditions and rapid burial are often cited as requisites for organic preservation and have been experimentally tested in this context (Allison, 1988, 2001; Briggs and Kear, 1993a). The second pathway, microbially mediated mineralization, is in some respects diametrically opposed to organic preservation. While organic preservation requires retardation of decay and preservation of the original biomolecules, authigenic mineralization relies on the fast action of microbes actively decaying structures to leave a characteristic chemical signature, be that through phosphatization, pyritization, or some other mechanism (Briggs, 2003). It has been demonstrated that this kind of mineralization can be induced in a lab setting on laboratory time scale; Briggs and Kear (1993b, 1994a) and Hof and Briggs (1997) were able to create conditions for calcium phosphate to form during the decay of crustaceans - in effect, a step towards creation of artificial fossils in the lab. Similar experiments also demonstrate the feasibility of mineralization of embryos (Raff et al., 2006; Hippler et al., 2012). Not only do experiments such as these enable identification of the conditions necessary for mineralization, but they can also unlock the nature of the specific mechanisms involved. For example, Raff et al. (2008) characterized the bacterial communities that comprise fossil forming biofilms, while Sageman et al. (1999) characterized the chemical microenvironments that are conducive to soft-tissue preservation. Consideration of the factors affecting rates of decay are therefore imperative to understanding both the mechanisms of organic preservation and authigenic mineralization.

A complementary aim to unlocking processes of preservation is the reconstruction of patterns of transformation and loss of data during that preservation process. In some ways, these aims are related, but they are considered here as addressing different methodological questions. Reconstructing taphonomic processes generally concerns chemical changes, while reconstructing patterns of morphological changes requires knowledge of anatomical changes. Patterns of morphological transformation during decay can take place on a macro-scale of whole individuals, through the sub-cellular or organelle level. For example, McNamara et al. (2013a) demonstrated that melanosomes (pigment organelles) are transformed during maturation in terms of their geometry, which has ramifications for interpretations of fossil color. At another sizelevel up, transformation of the morphology of giant bacteria and metazoan embryos during decay has been used to frame interpretations of fossils of disputed affinity (Raff et al., 2006; Cunningham et al., 2012a, b). At the level of body structures, Briggs and Kear (1994b) related the series of morphological changes taking place during decay in the muscle arrangement of amphioxus in relation to the muscle arrangement of fossil conodonts, while Sansom et al. (2013) reconstructed sequences of transformation of vertebrate anatomical complexes, such as feeding apparatus, appendages, skull, etc. At the level of whole animals, transformations in the arrangement of bodies during decay can shed light on fossil interpretations; e.g., decay of modern 
branchiopod carapaces and appendages related to preservation of fossil branchiopods (Orr et al., 2008). Like sequences of change and transformation, sequences of loss can be tested in the context of taphonomic patterns. Sansom et al. (2010b, 2011) experimentally derived relative sequences of loss of vertebrate morphological characters during decay to inform fossil interpretations. Loss can also be experimentally investigated at the level of community rather than at the individual level. Experimental decay of a variety of organisms (e.g., molluscs, arthropods, wood) in brine seeps (Parsons-Hubbard et al., 2008) and hydrothermal vents (Little, pers. com.) can reveal which taxa are susceptible to decay and which might be preserved in these particular circumstances. These different approaches make it possible to relate the transformation and loss of features to taphonomic biases at the level of organelles up through anatomical structures, individuals, and communities. Experimentally derived patterns of morphological change and loss are often intended for direct comparison with particular fossil clades or structures due to the phylogenetic constraint of the model data. In the case of experimentally derived data regarding mechanisms of preservation, results are applicable to more general situations due to the perceived universality of biogeochemical processes.

\section{DESIGN: HYPOTHESES AND VARIABLES}

Experimental taphonomy seems straightforward in a practical sense: observe an organism following death and note any changes. For example, Breder (1957) made observations as to the fate of the departmental fish that died from neglect in the laboratory tank, and the 'evil smelling pastes' that resulted. There is a long tradition of aktuopaläontologie (actualistic paleontology), but this kind of observational approach is poorly constrained (Briggs, 1995). Utilization of experimental methodology enables replication of results and a clearer understanding as to how particular variables affect outcomes. Indeed, Sansom et al. (2010b) were able to replicate the principal results of Briggs and Kear (1994b) only because the experimental variables were explicitly constrained in both studies. Constraining variables is not a trivial task for experimental taphonomy. The large number of variables (see below) means that a daunting multidimensional space of potential outcomes exists. Nevertheless, experimental constraints make it possible to build in additional variables to previously conducted experiments, and make it possible to produce clearer links with the paleontological data in question. Without experimental constraints, results from a taphonomic investigation risk being meaningless. Two approaches might be taken when constraining variables. First, when aiming to shed light on a particular fossil taxon from a particular fossil deposit, it might be appropriate to directly replicate the conditions inferred to exist at that particular time. However, this approach has the practical limitation that accurately replicating the conditions of any fossil deposit requires confidence in the estimation of those parameters. Such confidence is unlikely given that any interpretation of the chemical, physical, or microbiological parameters particular to a fossil locality will also be limited by incomplete data and taphonomic changes occurring over time. The second approach, which is more common, is to simplify variables as much as possible to create a working generalized taphonomic model of decay to which additional parameters can be subsequently factored in.

It is not common practice for hypotheses to be explicitly laid out for taphonomic experiments. What is a control and what is a hypothesis in a decay experiment? This depends on the intended aims of the experiment (see above). If no decay data exists for a molecule or structure in question, comparison could be made with an absence of decay (i.e., the original living condition), although this is not strictly a control. In some instances, an experimental vessel with no decay subject might be an appropriate control (Hammarlund et al., 2011). Regarding hypotheses, the given aim of Sansom et al. $(2010 b, 2011)$ was to evaluate phylogenetic affinities of vertebrate taxa; thus, the stated hypothesis was that synapomorphies will decay at random with respect to their phylogenetic informativeness. Hypotheses can also relate to mechanisms; Darroch et al. (2012) explicitly tested a geological hypothesis for Ediacaran taphonomy - the microbial deathmasks model-using experimental decay. In another example, Cunningham et al. (2012a) tested the hypothesis that decaying giant sulfur bacteria could replicate the morphologies observed in Ediacaran Doushantuo microfossils. The most general and basic hypothesis for a taphonomy experiment might be that no reliable pattern or process will be observed over the course of the experiment (i.e., results are 
random); this is not particularly hard to overturn given pattern-hungry human eyes (although Brock et al., 2006 found no clear patterns). In the eventuality that decay data already exist for a model molecule or structure, a suitable control would be the previously observed pattern or process (preferably replicated), and a suitable hypothesis that the conditions under investigation have no effect on the previously observed pattern or process. In either case, a clear relationship between the aim and the hypothesis being tested will always be necessary, and any hypothesis requires clearly defined variables. The variables pertinent to taphonomy experiments are evaluated below. They are grouped as relating to the organism being decayed (phylogeny, ontogeny, history) or the environment of decay (biological, chemical and physical; Figure 1).

\section{Organismal variables}

Phylogeny.-Among the most important variables for taphonomy experiments are those concerning the subject organism being decayed. Principal among organismal variables is phylogeny-i.e., what class of organism is being decayed. The type of organism being decayed needs to be kept in mind for experiments investigating either patterns or processes. The type of organism is relevant to patterns because morphology varies with respect to phylogeny, and relevant to processes because the biomolecules or histology of different organisms might undergo different processes. A single taxon could be used as an experimental proxy in cases where a very specific problem is being addressed, e.g., preservation of Carboniferous conchostracans (Orr et al., 2008) or preservation of freshwater bivalves (Skawina, 2010). In many cases, however, the aims are more phylogenetically broad.

Reconstructing the decay and preservation of distantly related organism or organisms with no suitable living proxy is more problematic. Graptolites, for example, are morphologically unlike any animal alive today. In this case, researchers rely on decay data from graptolites' closest living relative (pterobranchs), which limits applicability (Briggs et al., 1995). Similar problems occur when attempting to find modern analogues for the unusual soft-bodied fauna from the Cambrian of China and Canada (Briggs et al., 1994), where intractable evolutionary and morphological distances exist between fossil taxa and their closest living relatives. The solution is to

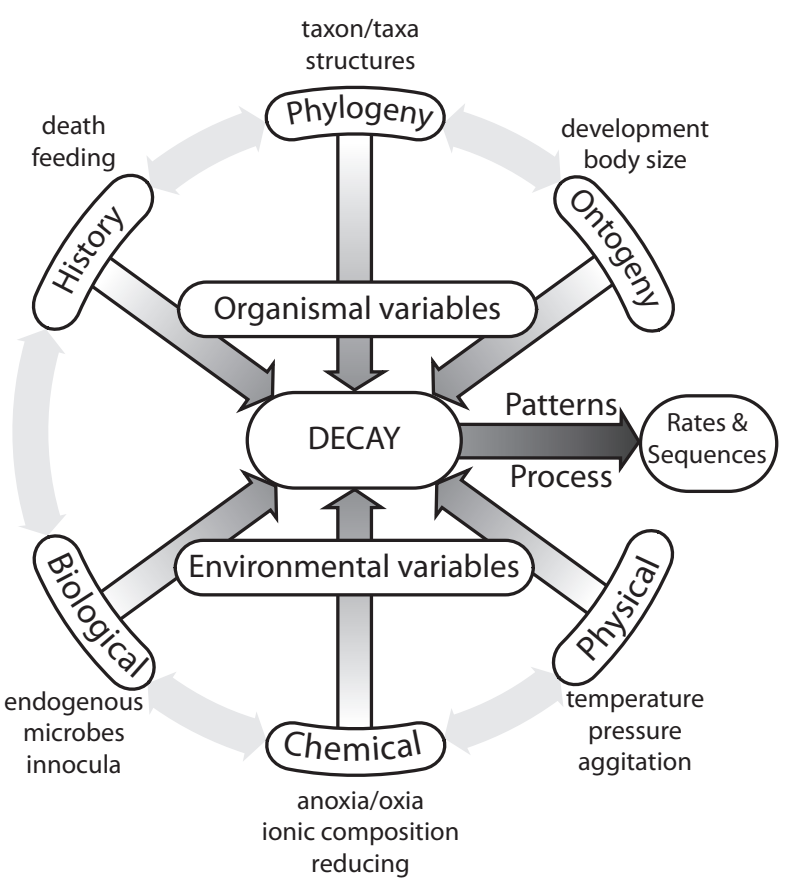

FIGURE 1.-Schematic representation of variables relevant to decay experiments.

apply the concept of an extant phylogenetic bracket to taphonomic patterns in the same sense that it might be applied in comparative anatomy (Sansom et al., 2013). If decay data exist from the closest living relatives, as well as an outgroup, taphonomic patterns common to those proxies can be applied to fossil taxa placed within that phylogenetic bracket (Sansom et al., 2013). This is especially important when close relatives exhibit different patterns of decay (e.g., Allison, 1988: Norway lobster and Baltic prawn). There is also some risk of circularity in choice of proxy. In cases where the affinity of a fossil taxon is subject to debate, choice of one particular taphonomic proxy might inflate the perceived similarity between proxy and fossil (Donoghue and Purnell, 2009). This problem is best avoided through application of taphonomic data from a broad phylogenetic range of taxa, although this may be intractable in some cases (e.g., the Ediacaran fauna for which affinities are unclear, Xiao and Laflamme, 2009).

Ontogeny.-Organisms not only vary with respect to their phylogeny, but also during their growth and development-i.e., their ontogeny. This can be especially important for fossil taxa that have been interpreted as representing nonadult stages of life (i.e., Orsten larvae, Doushantuo embryos). In these cases, the choice 
of an appropriate ontogenetic stage as subject for decay is more important than phylogenetic affinity. Gostling et al. (2008) used cleavage-stage embryos of tunicates, annelids, and mollusks as proxies for 'metazoan' fossil embryos; embryos at this stage are unlikely to differ greatly with respect to phylogeny, and their decay was not found to differ from results from echinoderms (Raff et al., 2006). Furthermore, Gostling et al. (2009) experimentally demonstrated that different ontogenetic stages of brine shrimp have different preservation potentials, which potentially accounts for preservation biases of Orsten-type fauna. Irrespective of the interpreted ontogenetic stage of the fossils in question, it is still suitable in some cases to use taphonomic data from proxies at multiple ontogenetic stages. The lamprey, for example, is a jawless vertebrate whose morphology is used as proxy for the early vertebrate condition, yet pre-metamorphosis juveniles (ammocoetes) and post-metamorphosis adults have morphologies more similar to nonvertebrate chordates and jawed vertebrates, respectively. Interpretation of soft-bodied fossil chordates therefore requires taphonomic data from both ontogenetic stages of lamprey growth (Sansom et al., 2010b, 2011).

Another variable loosely related to ontogenentic factors is the size of an organism. Body sizes vary by orders of magnitude both with respect to volume and mass. This can be true of just adult stages as well. In adult organisms with the same morphology, it is likely that patterns of transformation and loss will be the same, but drastic differences in size may well affect the biogeochemical processes and rates of decay.

History.-How an organism dies might have ramifications for the rates and sequences of decay that follow. It is desirable to maintain as much of the morphology of the living organism as possible, and not to systematically distort morphology of the subject, or its endogenous microbial flora, through death in any way. For this reason, exposure to anoxic conditions in an anaerobic cabinet is often used (e.g., Allison, 1988; Briggs, 1993a, 1994a, b; Gostling et al., 2008). This can be problematic, however. Some organisms exhibit a natural tolerance to anaerobic conditions so it can be tricky to accurately constrain the time of death (e.g., annelids, hagfish). Constraining time of death is paramount because it marks the point from which all measurements of duration of decay are made, and it enables patterns to be constructed using data from different individuals. For example, Briggs and Kear (1993a, p. 100) "killed [annelids] by gripping behind the pharynx region with blunt forceps, and suspending the head (only) in a stream of hot water...," while Freedman (1999) tried freezing hagfish, although $-20^{\circ} \mathrm{C}$ was found to not be cold enough for death to occur (hagfish were found to be very hard to kill, yet also hard to keep alive). In both cases, mechanical disruption occurred to the subject, but was deemed preferable to an 'unnatural toxin' that might kill bacteria (Briggs, 1995, p. 542). Sansom et al. (2010b, 2011, 2013) used an overdose of tricaine (MS-222), which is a common method of anesthesia for marine animals and has only a minor effect on bacteria when used at low concentration and with a buffer (Fedewa and Lindel, 2005). Sansom et al. (2010b, 2011, 2013) also found no differences from the sequences of decay identified by Briggs and Kear (1994b) for amphioxus. Another factor that may affect the endogenous microbial flora of the subject organism is the feeding regime immediately before death; recent feeding, and the foodstuffs given, may well affect the internal gut flora of a metazoan subject. In all of these cases, the mechanism of killing becomes a constraint in experimental design.

\section{Environmental variables}

Biological environment.-Bacteria are important agents of decay and decomposition (Briggs, 2003). Their inclusion or exclusion from experiments can have massive ramifications for rates and sequences of decay. All subjects have a natural endogenous microbial flora of some kind, yet this could vary according to the history of the organisms: i.e., its ecology, time in the lab, phylogeny, mechanism of death, etc. Eliminating endogenous microbes is difficult, however. Briggs and Kear (1993a) used gamma irradiation, but this resulted in additional morphological damage. Alternatively, Raff et al. (2008) used rifampicin to inhibit bacteria. This approach is less likely to have unintended morphological consequences, but does not eliminate all microbial activity; the role of archaea and fungi in decay of soft tissues is not well characterized, but they likely do play a role of some kind. One possibility is to introduce a standard microbial agent via a constrained inoculum. Briggs and Kear (1993) used naturally occurring estuary water and yeast substrate as a bacterial inoculum for decay experiments. They found significant differences in decay rate 
between aerobic trials with endogenous microbes with and without inocula. A standardized inoculum (Briggs and Kear, 1993a, b, 1994a, b; Briggs, 1995), works to constrain much of the biological environment within and between experiments. There is, however, extremely high variability with respect to microbial flora. Microbial biodiversity could be expected to vary in natural settings with respect to location, environment, microenvironment (e.g., extracted at surface, or $15 \mathrm{~cm}$ depth), temperature, tides, seasons, ocean currents, time of day, time between collection and utilization, method of storage, etc. There may also be interactions between microbial floras and the decaying organism or experimental environment (i.e., the same flora might have varying responses on different taxa). This can be especially important when microbial mats are being used as the agent of decay and preservation (Darroch et al., 2012; Iniesto et al., 2013). An alternative approach to trying to constrain this very complex variable is to characterize the bacteria that are present during decay. Raff et al. (2008) used 16S rDNA sequencing to characterize bacterial populations comprising decay biofilms under different conditions, with and without inoculum. This enabled them to subsequently use single cultured strains in individual experiments to identify the contingent interactions among bacterial species necessary for fossilization (Raff et al., 2013).

Chemical environment.-The division between chemical and biological environment presented here is somewhat artificial because the effects of the chemical environment on decay are largely through alteration of biological processes. Nevertheless, with respect to experimental design, these are considered as separate elements. Perhaps the simplest chemical factor relevant to decay is the availability of oxygen. Briggs and Kear (1993) investigated this factor thoroughly using open, closed, and completely sealed systems, deoxygenated water and air, and various combinations of these parameters. Even with ready access to air, oxygen saturation crashed rapidly at the onset of decay. This was confirmed by the detailed analysis of Sagemann et al. (1999) who identified anaerobic microenvironments forming around decaying carcasses. A significant reduction in decay rate was seen only following the complete elimination of oxygen (i.e., deoxygenated air and water, sealed aluminum bag; Briggs and Kear, 1993a). Kidwell and Baumiller (1990) also found no significant difference between decay rates in anoxic and oxic environments, yet Gostling et al. (2009) did. The relationship between volume of subject and volume of media (i.e., water) could also be relevant in this context, given potential exhaustion of initially available saturated oxygen.

In addition to access to oxygen, the chemistry of the medium of decay itself (e.g., water) is also highly relevant. Artificial seawater is one of the most commonly used media, which enables constraint of a number of factors, especially mineral composition of the water. The concentration of various dissolved ions is extremely relevant to mineralization experiments (Briggs and Kear, 1994a, Martin et al., 2005). Salinity has large ramifications for an experiment not only through interaction with the microbial flora, but also for the applicability of the results to a particular geological deposit (Allison, 1988, 1990). It is necessary, however, for the environment of decay to match the natural environment that the subject organism is adapted to and lived in. For example, Sansom et al. (2011) compared decay of hagfish and lamprey, but each were decayed in different environments reflecting their natural habitat (artificial seawater and deionized freshwater, respectively). Mismatch between environment and subject organism could lead to unnatural osmotic disruption of tissues, although in some instances this might be relevant to the experimental aims. For example, Gupta and Pancost (2004) decayed terrestrial plant leaves in both marine and freshwater environments, and revealed taphonomic differences. The $\mathrm{pH}$ of the medium of decay is also relevant in this context, given the impact on mineralization (Briggs and Wilby, 1996). $\mathrm{pH}$ is often investigated as a response variable (Briggs and Kear, 1993a), but less often as a independent variable (Brock et al., 2006).

Another variable, the presence of sulfide and sulfate, is expected to have wide ramifications for soft-tissue preservation (Xiao and Knoll, 1999; Hammarlund et al., 2011; Gaines et al., 2012). Reducing conditions can be replicated experimentally in the lab with the use of thiols (i.e., beta-mercaptoethanol) rather than hazardous $\mathrm{H}_{2} \mathrm{~S}$ (Raff et al., 2006). This will cause reduction of S-S bonds in proteins of the subject organism and therefore halts autolysis, the biological process by which cells (and therefore tissues) of the subject degrade. Reducing conditions such as these have been found to severely reduce rates of decay by limiting both autolysis and bacterial 
action (Raff et al., 2006, 2008; Gostling et al., 2008). Hammarlund et al. (2011) undertook a detailed investigation of the effect of sulfate availability on soft-tissue decay, and found retardation of decay in low sulfate settings.

Another highly relevant chemical factor is sediment. After all, fossils are found in rocks, not water. The use of sediment in experimental decay introduces both logical and practical challenges. The range of potential sediments that could be used is near infinite. Estuarine sediments have been used to investigate pyritization (Brock et al., 2006) and mineral attachment to soft tissues (Martin et al., 2004) during decay. Allison (1988) used specimens buried in sediments from a variety of locations to assess rates of morphological decay, and characterized the general mineral composition and granularity of the sediments. Hammarlund et al. (2011) also buried specimens in clay slurry that was characterized in terms of composition. Sediments can also introduce compounding variables which may need to be accounted for (e.g., microbial flora; Darroch et al., 2012). Furthermore, sediments vary not only in their chemistry and biology, but also physical grain size, which has ramifications for porosity of the surrounding medium. Explicit testing of the role of different sediments and minerals in decay as an independent variable is not common. This could be due in part to the scale of the variability of this factor, but also to the practical difficulties of extracting data from buried sediments without disruption. This is especially relevant when studying patterns of morphological transformation. One solution is the application of 3-D tomography (e.g., Hammarlund et al., 2011; Iniesto et al., 2013), but this is currently expensive, and it is hard to detect subtle differences in densities of entirely soft tissues when scanning. Given sediment variability and practical difficulties, initially establishing a null model for decay in water should be suitable in many cases. Such models can be used as controls for further analysis that would incorporate the use of sediments.

Physical environment.-The physical environment is also expected to interact strongly with biological and chemical environments. Given the importance of rates of change to decay experiments, temperature needs careful consideration as a variable. Temperature should ideally be kept constant for an individual specimen over the course of its decay. It could be expected that rates of decay are higher at higher temperatures, but not necessarily that the patterns of transformation will change. Sansom et al. (2010b) found the same sequences of loss of Branchiostoma characters at both $15^{\circ} \mathrm{C}$ and $25^{\circ} \mathrm{C}$, but at different rates. Higher temperatures can be used to accelerate processes on a laboratory time scale, but only within limits; microbial death due to high temperatures causes reduction in rates of decay (Arnosti et al., 1998). In the case of maturation, much higher temperatures are applied for shorter periods of time. Gupta et al. (2006, 2011) used elevated temperatures $\left(350^{\circ} \mathrm{C}\right)$ to artificially mature chitin. McNamara et al. (2013b) compared the effect of normal decay (18 months at $\left.25^{\circ} \mathrm{C}\right)$ with artificial maturation (200$270^{\circ} \mathrm{C}$ ) on color structures of insects, and only found significant alteration for maturation. Artificially high pressures are also relevant in this context (Gupta et al., 2006; Gupta, 2011; McNamara et al., 2013b) but seemingly not to the same degree as temperature (McNamara et al., 2013a, b). Physical pressure (i.e., compression) has also been investigated, e. g., examining changes to morphology of velvet worms (flattened under 17kg; Monge-Nájera and Hou, 2002) and feathers (flattening in a printing press; Foth, 2012), although neither could be expected to be suitable representations of taphonomic processes.

Physical agitation is also relevant to decay. Kidwell and Baumiller (1990) tumbled specimens of echinoderms over two days to study the factors that affect their disarticulation. Physical agitation is more relevant to the preservation of skeletons rather than soft tissues, although Duncan et al. (2003) investigated the effect of transport (agitation in water flumes) on the disarticulation rates of cockroaches. Another physical factor rarely considered in a taphonomic context is access to light. Decaying subjects should be placed in the dark because light may distort the growth of microbial floras.

\section{Outputs}

How to best measure or quantify decay? This again depends on the aims of the experiment. One of the most straightforward metrics is weight loss -i.e., the percentage of the original organic material of the organism that has been lost to decay processes. This can prove problematic, however. Wet weights are extremely variable due to osmotic uptake, structural integrity and method of extraction (Briggs, 1995), while dry weights 
requires destructive sampling and accurate knowledge of the ratio between standard wet:dry weights (Briggs and Kear, 1993a). pH can also be measured as a response variable (e.g., Briggs and Kear, 1993a), but pH changes are only indirectly related to decay, and other processes will have an effect on $\mathrm{pH}$. Weight changes, whether wet or dry, and potentially $\mathrm{pH}$, can be useful for comparing relative rates of decay, but are limited in the information they provide about processes of decay or patterns of morphological decay. With respect to processes of decay, other chemical changes can be assessed and quantified. For example, changes to aliphatic composition of chitin (Gupta et al., 2006), lipids (McNamara et al., 2013b), or minerals (Briggs and Kear, 1994a) of arthropods have been used as quantitative measures of decay. In this later case, a percentage reduction in organic carbon and increase in phosphate over the course of decay supports mineralization as the process pathway for decay and potential preservation. Alternatively, Hammarlund et al. (2011) calculated rates of decay using first-order decay constants based on outflux of dissolved organic carbon.

When reconstructing patterns of morphological transformation, a direct measure of morphology is necessary. This can be straightforward when the aim is to address one specific morphological variable, e.g., the geometry of melanosomes (McNamara et al., 2013a). Trying to reconstruct morphological change of specimens at the level of whole, complex bodies presents a bigger challenge. One common approach is to identify specified 'stages' of decay (e.g., Briggs and Kear, 1993a; Gostling et al., 2009; Sansom et al., 2011). These stages are identified $a$ posteriori and are defined according to particular criterion (e.g., body flaccid) or combination of criteria (e.g., loss of muscles and swollen gut). These stages are qualitative, but can be mapped onto timescales or treated quantitatively by considering percentage of specimens at any particular stage (Gostling et al., 2009). Use of identified decay stages has the advantage of being a relatively simple and quick approach: observations can often be made externally, identified stages can be used as a point of reference in future experiments, and stages can be applied directly to the fossil record. There are limitations to this approach. The taxon-specific nature of decay stages makes it difficult to directly or quantitatively compare results from different taxa, even those closely related.
Furthermore, while efforts are made to identify stages that are discrete, decay is complex and a continuum; different sequences of decay can be observed in different specimens, and stages can overlap. Quantifying stages or mapping changes in stages through time will therefore only represent an imperfect generalization of results. An alternative is to quantify morphological change in terms of number of characters decaying and lost, using anatomical features as the unit of investigation rather than bodies. Sansom et al. (2010b, 2011) considered the decay of each individual morphological character (apomorphy) of a specimen through the decay process, and classified them as belonging to defined categories (i.e., pristine $=1$, decaying $=0.5$, lost $=0$ ). Using this kind of approach enables specimens and characters to be plotted through time in terms of their percentage completeness. This provides a more objective quantitative measure that can be compared between taxa. Nevertheless, results might not be directly comparable because different taxa will have different suites of characters, and categorization of decay states might not be consistent between observers.

Practically speaking, the chosen measure of decay will also dictate the kind of sampling necessary. External sampling (e.g., photography or visual recording of information) is generally preferable because it is quicker and enables a greater number of specimens to be analyzed with the same resources (Fig. 2). In many cases, however, destructive sampling is necessary, either because internal anatomy is relevant, or because visual observations are not possible (e.g., buried specimens, specimens obscured by biofilms or cloudy water). Experimental vessels with flat surfaces rather than round surfaces (e.g., jar) enable a greater clarity for photography. Extraction and dissection requires a careful hand and consistent application (Fig. 2). Destructive sampling also requires a greater number of specimens. The number of specimens necessary to obtain a consistent signal, either for an experimental or a sampling interval of an experiment depends on the aims of the experiment as well as the variability of the model system being investigated. It may also be necessary to consider the number of replicates needed for statistical significance for intended comparisons.

Some of the methods for measuring decay presented here will undoubtedly prove useful in future taphonomy experiments. There is, however, a wide variety of measures that could be used. 

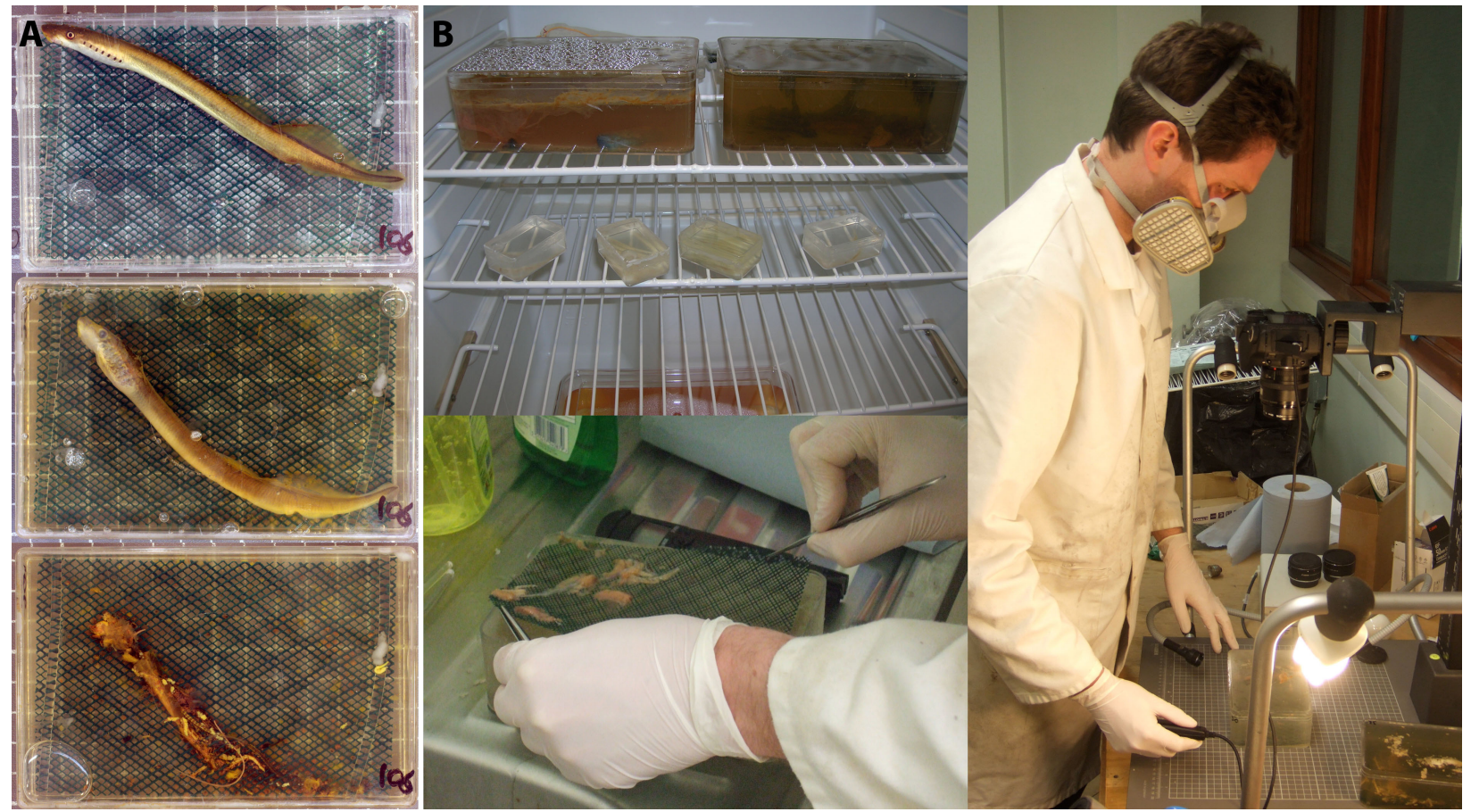

FIGURE 2.- In an experimental decay laboratory. A) Sequence of morphological decay of an adult lamprey. B) Storage, extraction, and photography of decaying specimens (far right and lower middle photos by Mark Purnell, featuring the author).

Innovation in this sense will depend on the aims of future experiments and the imagination of researchers.

\section{APPLICATION: PRINCIPLES AND EXAMPLES}

As shown by the numerous examples and variables presented above, experimental decay has yielded a wealth of data. Applying these data to the fossil record is the obvious goal, but requires careful consideration. For experiments including a wide variety of variables, comparison of results with paleontological data might inform interpretations of the processes underlying the formation of particular fossils. For example, if the chemistry or morphology of fossils in a particular deposit match the chemistry or morphology identified under one set of experimental parameters but not a second set of experimental parameters, the first set of parameters could be interpreted as playing a role in fossil preservation. Alternatively, a priori knowledge of the mode of preservation of a fossil deposit will aid in application of experimental results. If fossils are interpreted as having been organically preserved, for example, preservation of characters or bodies identified as slow to decay should be expected, along with loss of those quick to decay. If bacterially mediated authigenic mineralization is the dominant mode of preservation in a deposit, the opposite will be true: characters or bodies identified as quick to decay might be expected to have a relatively enhanced probability of preservation. Application of patterns of morphological transformation and loss to the fossil record therefore requires knowledge of the preservational mechanisms in play because it can reverse interpretations applied. Given this potential 'chicken-or-the-egg' situation, using the same set of experimentally derived decay data to simultaneously evaluate the process of preservation of a fossil and the morphology or affinity of that fossil can risk problematic circularity.

In all instances, it is necessary to ask whether the experimental parameters are a realistic framework for interpretation given the parameters of any particular fossil. As discussed above, the potential environmental variables of any decay experiment are numerous, as are the geological parameters of a fossil deposit. In cases where there is reliable data regarding geological parameters of a deposit, and those parameters are in accordance with experimental conditions, it is possible to have greater confidence in the 
application of decay data. Similarly, in cases were there is extensive experimental data from different environmental conditions, there should be greater confidence in application of that decay data to fossil deposits. The optimum situation is obviously a combination of reliable geological interpretations and extensive experimental data. The question of applicability should also be asked of the organismal variables -i.e., phylogeny and ontogeny. Is the organism or tissue used in a decay experiment a suitable model for comparison with the fossil in question? Like the environmental variables, if experimental data for a range of organisms that cover the potential affinities of the fossil organism exist, or reliable independent data regarding the affinity of the fossil organism exist, it is possible to have greater confidence in the application of decay data.

The application of experimentally derived decay data to the fossil record can shed light on a range of different problems. The case studies below illustrate how the anatomy, preservation, or evolutionary significance of fossils can be revised or elucidated, and how the principles outlined above can be applied.

\section{Correcting interpretations of fossil color}

The preservation of soft tissues has enabled the reconstruction of the color of some fossil organisms, most notably in birds and their dinosaur relatives (e.g., Vinther et al., 2008; Barden et al., 2011; McNamara, 2013). Fossil color provides a unique insight into not only the morphology of these long extinct organisms, but their ecology and behavior. Interpretations of color in fossil feathers have utilized the variability of geometry of melanosomes in that melanosomes of different colors tend to have different shapes (Li et al., 2010). This inference is reliant, however, on a direct comparison between extant and fossil melanosomes.

McNamara et al. (2013a) tested the hypothesis that taphonomic processes do not alter the geometry of melanosomes. Regarding organismal variables, they tested feathers of a wide variety of melanosome types from a wide variety of Neornithes (modern birds). Regarding physical environmental variables, feathers were subjected to high temperature and high pressure maturation for 24 hours $\left(250 \mathrm{bar}, 200\right.$ and $\left.250^{\circ} \mathrm{C}\right)$. In terms of outputs, geometric changes (long axis and short axis) were assessed, with the fresh condition representing the control. They identified a common taphonomic pathway whereby melansomes shrank during maturation, less so at lower temperatures (Fig. 3A). When applying this finding to the fossil record, however, it is necessary to ask whether the experimental variables match the paleontological case. The wide variety of types of melanosome tested, as well as taxonomic coverage, indicate that these results are likely to be consistent for all birds. Stem-group birds (including dinosaurs) fall outside this extant phylogenetic bracket and therefore might not necessarily be expected to follow the same pattern; outgroup analysis might not be informative in this context because nonavian reptiles lack feathers (although see Li et al., 2014). With respect to environmental variables, McNamara et al. (2013a) found different taphonomic pathways at different temperatures, and related this to the parameters of particular fossil deposits. The Yixian Formation has been interpreted as having high burial depths and temperatures, and thus melanosomes from dinosaurs from the Jehol Biota might have been more transformed than those from other formations. Given these geological parameters, interpretations of plumage patterns of dinosaurs from the Jehol Biota will need revision in light of taphonomic transformation of melanosomes. It remains to be seen whether there are proportional differences during this transformation; uniform shrinkage could be corrected for (Li et al., 2014). Similar temperature-related transformation has been observed in insect experiments as well (McNamara et al., 2013b).

\section{Feasibility of ancient fossil embryos}

The Ediacaran Doushantuo Formation from south China has yielded remarkable fossils from a crucial interval in the history of life. These tiny microfossils exhibit a range of multicellular morphologies that have been variously interpreted as bacteria, algae, and embryos of animals (Cunningham et al., 2012b). These varying interpretations have extremely different ramifications for interpretations of the evolution of life on Earth. Experimental decay has been used to investigate the affinities of these organisms and the mechanisms that might underlie their formation; in this instance, taphonomic patterns and processes are very much intertwined. The analyses of Martin et al. (2004, 2005), Raff et al. (2006, 2008, 2013), Gostling et al. (2008, 2009), and Cunningham (2012a) provide a wealth of experimentally derived data relevant to Doushantuo Formation fossils. 

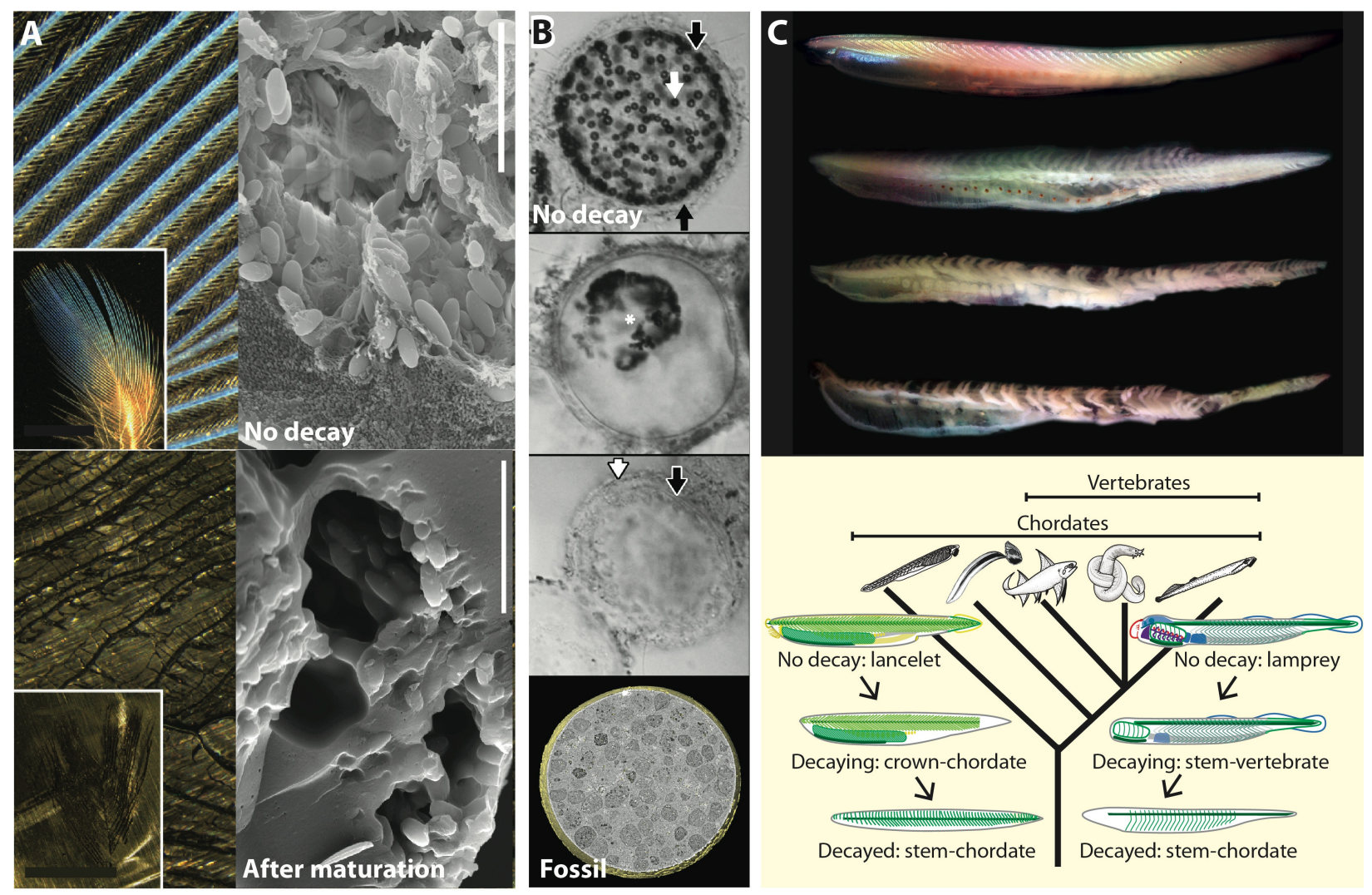

FIGURE 3.-Case studies of experimental decay. A) Feathers before and after maturation at $250^{\circ} \mathrm{C}$ and 250 bar pressure indicating shrinkage and distortion of internal melanosomes (scale bars $=5 \mu \mathrm{m}$ ). B) Giant sulfur bacteria (Thiomargarita) undergoing decay coalesce vesicles on the surface of their vacuole, not internally, which contrasts with the Ediacaran fossil Tianzhushania. C) Amphioxus undergoing character loss during 60 days of decay. The systematic loss of synapomorphies in amphioxus and juvenile lamprey (ammocoete); as decay progresses, the organisms is interpreted as further down the phylogeny from its true position (stemward slippage). (A) From McNamara et al. 2013a; (B) from Cunningham et al. 2012a; (C) modified from Sansom et al. 2010b; photographs edited by Mark Purnell.

Cunningham et al (2012a) explicitly tested the hypothesis that decaying giant sulfur bacteria could replicate the morphologies observed in Doushantuo microfossils. Regarding their organismal variables, a natural subject choice was the giant sulfur bacteria Thiomargarita. They also used early embryonic stages of sea urchins (thus considering phylogenetic and ontogenetic variables). The history of the subject organisms is also relevant in this context; reducing conditions (BME) were used to kill subjects, but proved problematic for giant sulfur bacteria. Regarding environmental variables, the biological environment was constrained by using sterile artificial seawater or sterile artificial seawater with the addition of an aerobic marine bacterium to induce pseudomorphing (i.e., mineral replication of morphology). Furthermore, preliminary trials were conducted under oxic, anoxic, and reducing conditions. Specimens were incubated for six days at $23^{\circ} \mathrm{C}$. Outputs from these experiments included identification of the changes in morphology and the comparative pseudomorphing of embryos and giant bacteria. These experiments revealed that the subcellular morphology characteristic of Doushantuo microfossils are not replicated during decay of giant bacteria (Fig 3B), and that bacterially mediated pseudomorphing occurs readily for animal embryos, but not giant sulfur bacteria. The giant sulfur bacteria interpretation of the microfossils is therefore called into question.

When combined with other experimental results (Martin et al., 2004, 2005; Raff et al., 2006, 2008, 2013; Gostling et al., 2008, 2009), a wide variety of taxa have been tested, and common taphonomic patterns were found with respect to different metazoans (e.g., chelicerates, crustaceans, echinoderms, and annelids). Again, the experimental focus on particular ontogenetic 
stages (i.e., embryos) is highly relevant in this context. When applying these findings to the fossil record, phylogenetic coverage and ontogenetic coverage of metazoans is comprehensive. However, a large phylogenetic, morphological, and therefore taphonomic gap, exists between metazoa and bacteria. This gap could be relevant given possible non-metazoan holozoan affinities (Huldtgren et al., 2011). Regarding environmental variables, the results of decay experiments have rarely been considered in light of the geological parameters of the Doushantuo Formation. Instead, the results from trials under different environmental conditions have enabled identification of circumstances that might be conducive towards preservation of fossils embryos, and the mechanisms that might allow their formation-i.e., reducing conditions, anoxia, and specific bacterial interactions. The combined results and analyses have therefore supported some interpretations of affinity, eliminated others, and provided a feasible mechanism for the fossilization of structures that are improbable candidates for preservation.

\section{Phylogenetic bias in chordates}

It is the combination of present and absent anatomical features (apomorphies) that is used to reconstruct the phylogenetic relationships and assess the evolutionary significance of a fossil. Soft-bodied fossils, however, are afflicted by data loss during preservation, whereby some apomorphies are transformed and decayed away. Sansom et al. (2010b, 2011) tested the hypothesis that loss of anatomical information (apomorphies) during decay occurs at random with respect to the class of anatomical information-i.e., specialized synapomorphic characters decay at the same rate of generalized plesiomorphic characters. Regarding subject variables, they used a range of soft-bodied extant chordates: the invertebrate amphioxus, and the vertebrates hagfish and lamprey (both adult and juvenile). Environmental variables were constrained to anoxia with endogenous microbes only. Specimens were incubated at $25^{\circ} \mathrm{C}$ for up to 300 days, with terminal sampling throughout that period. Decay was quantified by scoring individual anatomical characters as pristine, decaying, or lost. A common taphonomic pattern was found whereby a strong correlation existed between the order of loss of soft characters during decay and the hierarchical order of characters in terms of the phylogenetic informativeness (i.e., synapomorphies decay before plesiomorphies; Fig. 3C).

As with the case studies above, it is necessary to ask whether the experimental variables match the paleontological case so this finding can be applied to the fossil record. With respect to the subject variables, the tested subjects represent a comprehensive sampling of non-biomineralized chordates, with the exception of urochordates. As such, the common taphonomic pattern can be applied to fossil taxa hypothesized as belonging to the chordates, including vertebrates, and potentially the chordate stem, because the extant phylogenetic bracket is covered by a consistent taphonomic signal. The data cannot, however, be directly applied to non-chordates. Regarding the environmental variables, the preservation mode is highly relevant in this context. Sansom et al. (2010b, 2011, 2013) compared the experimentally derived data and patterns with extinct putative chordates from Burgess Shale-type deposits where the dominant mode of preservation of soft tissues is through the organic pathway (Butterfield, 2003; Gaines et al., 2012). Under these circumstances, slowly decaying characters are expected to have a higher probability of survival in a fossil, while characters quick to decay will be lost. As such, organically preserved fossil chordates are likely to be missing synapomorphies, leaving a generalized plesiomorphic chordate condition; systematic loss of data during preservation therefore causes fossils to be interpreted as belonging to the stemlineage of a clade when they in fact belong in the crown. In deposits where authigenic mineralization is the dominant mode of preservation, decay bias has a different effect; synapomorphies are preserved, and crown-group organisms are recognized as such. Stem-group organisms that posses fewer synapomorphies and largely comprise plesiomorphies are less likely to be preserved; this will cause a 'stem deficiency,' whereby stem organisms are missing and the early stages of a clade are unknown.

In this case study, a general taphonomic pattern reveals consistent biases in the phylogenetic interpretation of fossils (also observed biomineralized organisms by Sansom and Wills, 2013). The resulting decay patterns can elucidate affinities of specific fossil taxa as either phylogenetically meaningful stem taxa (e.g., Haikouichthys), or taphonomically suspect stem taxa (e.g., Cathaymyrus) (Sansom et al., 2010a, b, 2011, 2013). A recent case in point is regarding 
the taxon Metaspriggina. Previously known from few poorly preserved specimens, it exhibited chordate plesiomorphies and was interpreted as an amphioxus-like primitive chordate, (Conway Morris, 2008, Briggs et al., 1994). Recent discovery of better preserved specimens, however, yielded a number of previously unknown vertebrate synapomorphies, thus causing the taxon to slide back up the stem (i.e., move up the tree towards the crown) (Conway Morris and Caron, 2014). A higher fidelity of preservation reversed the effect of stemward slippage. In all of these cases, consideration of phylogenetic shifts resulting from taphonomic biases is only possible through consideration of the mode of preservation at relevant fossil deposits.

\section{CONCLUSIONS}

Experimental decay is a powerful tool with which to evaluate the fossil record of soft tissues. As with all experiments, however, taphonomic studies requires careful consideration of the relationship between their aims, design, variables, and applicability. Aims can relate to understanding the processes by which soft tissues become preserved in the fossil record, or elucidating patterns of transformation and loss of morphologies during that preservation. A clear knowledge of experimental aims enables explicit articulation of the hypothesis being tested. What is the control? What are the independent variables (inputs)? What are the dependent variables (outputs)? As discussed above, the high number of possible variables in the context of decay, from the phylogeny or ontogeny of the subject through the biological, chemical, and physical environment, means that a vast, multidimensional space of potential outcomes exists. This can be compensated for through utilization of explicit experimental hypotheses and constraint of variables. The application of experimentally derived decay data to the fossil record requires clear understanding of how these experimental variables relate to the geological variables. It is hoped that the principles outlined here will benefit future decay experiments, and serve as framework that can be built upon. It is anticipated that many innovations and discoveries are yet to come in the field of soft-tissue decay and preservation, not only though application of existing techniques, but also through the development of new analytical techniques to as-yet untested areas.

\section{ACKNOWLEDGMENTS}

The manuscript benefited from general discussions with Mark Purnell and Sarah Gabbott (Leicester), and the advice of John Cunningham (Bristol) regarding Doushantuo embryos. John Cunningham and Maria McNamara (Cork) kindly provided images for Figure 3 and Mark Purnell for Figure 2. Thanks to Marc Laflamme, Jim Schiffbauer, and Simon Darroch for the invitation to contribute to this volume, and to NERC for providing financial support (fellowship NE/ I020253/1). This manuscript benefitted from the critical feedback of Simon Darroch and Mark Purnell.

\section{REFERENCES}

Allison, P. A. 1988. The role of anoxia in the decay and mineralization of proteinaceous macro-fossils. Paleobiology, 14:139-154.

Allison, P. A. 1990. Variation in rates of decay and disarticulation of Echinodermata: Implications for the application of actualistic data. PALAIOS, 5:432-440.

Allison, P. A. 2001. Decay, p. 270-273. In D. E. G. Briggs and P. R. Crowther (eds.), Palaeobiology II. Wiley-Blackwell.

Arnosti, C., B. B. Jorgensen, J. Sagemann, And B. THAMDRUP. 1998. Temperature dependence of microbial degradation of organic matter in marine sediments: polysaccharide hydrolysis, oxygen consumption, and sulfate reduction. Marine Ecology Progress Series, 165:59-70.

Barden, H. E., D. Wogelius, D. Li, P. L. MAnNing, N. P. Edwards, AND B. E. VAN Dongen. 2011. Morphological and geochemical evidence of eumelanin preservation in the feathers of the Early Cretaceous bird Gansus yumenensis. PLos ONE, $6: \mathrm{e} 25495$.

BREDER, C. M. 1957. A note on preliminary stages in the fossilization of fishes. Copeia, 3:662-663.

BRIGGS, D. E. G. 1995. Experimental taphonomy. PALAIOS, 10:539-550.

Briggs, D. E. G. 2003. The role of decay and mineralization in the preservation of soft-bodied fossils. Annual Reviews in Earth and Planetary Sciences, 31:275-301.

Briggs, D. E. G., D. H. ERwin, AND F. J. Collier. 1994. The Fossils of the Burgess Shale. Smithson Institution Press, Washington, D. C.

Briggs, D. E. G., R. P. Evershed, AND M. J. LOCKHEART. 2000. The biomolecular palaeontology of continental fossils. Palaeobiology, 26:169-193.

BRIGGS, D. E. G., AND A. J. KEAR. 1993a. Decay and preservation of polychaetes: taphonomic 
thresholds in soft-bodied organisms. Paleobiology, 19:107-135.

Briggs, D. E. G., AND A. J. KeAR. 1993b. Fossilization of soft tissue in the laboratory. Science, 259:1439-1442.

BriggS, D. E. G., AND A. J. KeAR. 1994a. Decay and mineralization of shrimps. PALAIOS, 9:431-456.

Briggs, D. E. G., AND A. J. KeAR. 1994b. Decay of Branchiostoma: implications for soft-tissue preservation in conodonts and other primitive chordates. Lethaia, 26:275-287.

Briggs, D. E. G., A. J. Kear, M. BaAs, J. W. DE LEEUW, AND S. RigBY. 1995. Decay and composition of the hemichordate Rhabdopleura: implications for the taphonomy of graptolites. Lethaia, 28:15-23.

BRIGGS, D. E. G., AND P. R. WILBY. 1996. The role of the calcium carbonate-calcium phosphate switch in the mineralization of soft-bodied fossils. Journal of the Geological Society, 153:665-668.

Brock, F., R. J. PARKES, AND D. E. G. BRIGgS. 2006. Pyrite formation associated with decay of plant material. PALAIOS, 21:499-506.

Butterfield, N. J. 2003. Exceptional fossil preservation and the Cambrian explosion. Integrative Comparative Biology, 43:166-177.

CONWAY MORRIS, S. 2008. A redescription of a rare chordate, Metaspriggina walcotti Simonetta and Insom, from the Burgess Shale (Middle Cambrian), British Columbia, Canada. Journal of Paleontology, 82:424-430.

CONWAY MORRIS, S., AND J.-B. CARON. 2014. A primitive fish from the Cambrian of North America. Nature, 512:419-422. doi:10.1038/ nature13414.

Cunningham, J. A., C.-W. Thomas, S. Bengtson, M. Stampanoni, F. R. TURner, J. V. BAiley, R. A. RAFF, E. C. RAFF, AND P. C. J. DONOGHUE. 2012a. Experimental taphonomy of giant sulphur bacteria: implications for the interpretations of the embryolike Ediacara Doushantuo fossils. Proceedings of the Royal Society, 279:1857-1864.

Cunningham, J. A., C.-W. Thomas, S. Bengtson, S. L. Kearns, S. Xiao, F. Marone, M. STAMPANONI, AND P. C. J. Donoghue. 2012b. Distinguishing geology from biology in the Ediacaran Doushantuo biota relaxes constraints on the timing of the origin of bilaterians. Proceedings of the Royal Society of London B-Biological Sciences, 279:2369-2376.

Darroch, S. A. F., M. Laflamme, J. D. SCHIFFBAUER, AND D. E. G. BRIGGS. 2012. Experimental formation of a microbial death mask. PALAIOS, 27:293-303.

Donoghue, P. C. J., AND M. A. PuRnell. 2009. Distinguishing heat from light in the debate over controversial fossils. BioEssays, 31:178-189.

Duncan, I. J., F. Titchenter, AND D. E. G. BRiggs.
2003. Decay and disarticulation of the cockroach: Implications for preservation of the blattoids of Writhlington (Upper Carboniferous), UK. PALAIOS, 18:256-265.

FEDEWA, L. A., AND A. LINDEL. 2005. Inhibition of growth for select gram-negative bacteria by tricaine methane sulfonate (MS-222). Journal of Herpetological Medicine and Surgery, 15:13-17.

FREEDMAN, K. 1999. Aspects of the taphonomy of jawless vertebrates. Unpublished Ph.D. dissertation, University of Leicester, $166 \mathrm{p}$.

Fотн, C. 2012. On the identification of feather structures in stem-line representatives of birds: evidence from fossils and actuopalaeontology. Paläontologische Zeitschrift, 86:91-102.

Gaines, R. R., E. U. Hammarlund, X. Hou, C. QI,S. E. Gabbott, Y. ZhaO, J. Peng, and D. E. CANFIELD. 2012. Mechanism for Burgess Shaletype preservation. Proceedings of the National Academy of Science of the United States of America, 109:5180-5184.

Gostling, N. K., X. Dong, And P. C. J. Donoghue. 2009. Ontogeny and taphonomy: An experimental taphonomy study of the development of the brine shrimp Artemia salina. Palaeontology, 52:169186.

Gostling, N. J., C.-W. Thomas, J. M. GreEnwood, X. Dong, S. Bengtson, E. C. RAFF, R. R. RAFF, B. M. Begnan, M. Stampanoni, and P. C. J. DoNOGHUE. 2008. Deciphering the fossil record of early bilaterian embryonic development in light of experimental taphonomy. Evolution \& Development, 10:339-349.

GuPTA, N. S. 2011. Transformation of chitinous tissues in elevated pressure-temperature conditions: Additional insights from experiments on plant tissues, p. 153-168. In N. S. Gupta (ed.), Chitin Formation and Diagenesis. Springer, London.

Gupta, N. S., R. Michels, D. E. G. Briggs, R. P. EVERshed, AND R. D. PANCost. 2006. The organic preservation of fossil arthropods: an experimental study. Proceedings of the Royal Society of London B-Biological Sciences, 273:2777-2783.

Gupta, N. S., And R. D. Pancost. 2004. Biomolecular and physical taphonomy of angiosperm leaf during early decay: Implications for fossilization. PALAIOS, 19:428-440.

GuPTA, N. S., AND R. E. SuMmONS. 2011. Fate of chininous organisms in the geosphere, p.133-152. In N. S. Gupta (ed.), Chitin Formation and Diagenesis. Springer, London.

Hammarlund, E., D. E. Canfield, S. Bengston, P. Mygind Leth, B. SChillinger, AND E. CAlzada. 2011. The influence of sulfate concentration on soft-tissue decay and preservation. Palaeontolographica Canadiana, $31: 141-156$. 
Hippler, D., N. Hu, M. Steiner, G. Scholtz, AND G. FRANZ. 2012. Experimental mineralization of crustacean eggs: new implications for the fossilization of Precambrian-Cambrian embryos. Biogeosciences, 9:1765-1775.

Hof, C. H. J., AND D. E. G. BRIGGS. 1997. Decay and mineralization of mantis shrimps (Stomatopoda: Crustacea)-A key to their fossil record. PALAIOS, 12:420-438.

Huldtgren, T., J. A. Cunningham, C. Yin, M. Stampanoni, F. Marone, P. C. J. Donoghue, AND S. BEngSTON. 2011. Fossilized nuclei and germination structures identify Ediacaran "animal embryos" as encysting protists. Science, 334:1696-1699.

InIESTO, M., A. I. LopeZ-ArChilla M. FregenALMartínez, A. D. Buscalioni, AND M. C. GUERRERO. 2013. Involvement of microbial mats in delayed decay: an experimental essay on fish preservation. PALAIOS, 28:56-66.

Kidwell, S. M., AND T. BAUMiller. 1990. Experimental disintegration of regular echinoids: Roles of temperature, oxygen, and decay thresholds. Paleobiology, 16:247-271.

Li, Q., J. A. Clarke, C. F. Zhou, Q. Meng, D. Li, L. D'AlbA, AND M. D. SHAWKey. 2014. Melanosome evolution indicates a key physiological shift within feathered dinosaurs. Nature, 507:350-353.

Li, Q., K.-Q. GaO, J. Vinther, M. D. Shawkey, J. A. Clarke, L. D'Alba, Q.-J. Meng, D. E. G. BRIGGS, AND R. O. PRUM. 2010. Plumage color patterns of an extinct dinosaur. Science, 327:1369-72. doi:10.1126/science. 1186290

Martin, D., D. E. G. BRiggS, AND J. PARKeS. 2004. Experimental attachment of sediment particles to invertebrate eggs and the preservation of softbodied fossils. Journal of the Geological Society, 161:735-738.

Martin, D., D. E. G. Briggs, And J. Parkes. 2005. Decay and mineralization of invertebrate eggs. PALAIOS, 20:562-572.

MCNAMARA, M. E. 2013. The taphonomy of colour in fossil insects and feathers. Palaeontology, 56:557575.

McNamara, M. E., D. E. G. Briggs, P. J. OrR, D. J. FIELD, AND Z. WANG. 2013a. Experimental maturation of feathers: implications for reconstructions of fossil feather colour. Biology Letters, 9:20130184. doi: 10.1098/rsbl.2013.0184

McNamara, M. E., D. E. G. BRiggs, P. J. ORR, N. S. Gupta, E. R. LOCATElli, L. QIU, H. YANG, Z. WANG, H. NoH, AND H. CAO. 2013b. The fossil record of color illuminated by maturation experiments. Geology, 41:487-490.

MONGE-NÁJERA, J., AND X. HoU. 2002. Experimental taphonomy of velvet worms (Onychophora) and implications for the Cambrian "explosion, disparity and decimation" model. Revista de Biología Tropical, 50:1133-1138.

ORR, P. J., D. E. G. BRIGGS, AND S. L. KEARnS. 2008. Taphonomy of exceptionally preserved crustaceans from the Upper Carboniferous of Southeastern Ireland. PALAIOS, 23:298-312.

Page, A., S. E. Gabbott, P. R. Wilby, And J. A. ZALASIEWICZ. 2008. Ubiquitous Burgess Shalestyle "clay templates" in low-grade metamorphic mudrocks. Geology, 36:855-858.

Parsons-Hubbard, K. M., E. N. Powell, A. RAYMOND, S. E. WALKer, C. BRETt, K. ASTONAlcox, R. N. Shepard, R. Krause, and B. DELINE. 2008. The taphonomic signature of a brine seep and the potential for Burgess Shale style preservation. Journal of Shellfish Research, 27:227-239.

Raff, E. C., M. E. Andrews, F. R. Turner, E. ToH, D. E. Nelson, AND R. A. RAFF. 2013. Contingent interactions among biofilm-forming bacteria determine preservation or decay in the first steps toward fossilization of marine embryos. Evolution \& Development, 15:243-256.

Raff, E. C., K. L. Schollaert, D. E. Nelson, P. C. J. Donoghue, C.-W. Thomas, F. R. Turner, B. D. Stein, X. Don, S. Bengtson, T. Huldtgren, M. StAMPANONI, Y. CHONGYU, AND R. A. RAFF. 2008. Embryo fossilization is a biological process mediated by microbial biofilms. Proceedings of the National Academy of Sciences of the United States of America, 105:19359-19364.

Raff, E. C., J. T. Villinski, F. R. Turner, P. C. J. Donoghue, AND R. A. RAFF. 2006. Experimental taphonomy shows the feasibility of fossil embryos. Proceedings of the National Academy of Sciences of the United States of America, 103:5846-5851.

Sageman, J., S. J. Bale, D. E. G. Briggs, and R. J. PARKES. 1999. Controls on the formation of authigenic minerals in associations with decaying organic matter: An experimental approach. Geochimica et Cosmochimica Acta, 63:10831095.

Sansom, R. S., K. Freedman, S. E. Gabbott, R. J. Aldridge, AND M. A. Purnell. 2010a. Taphonomy and affinity of an enigmatic Silurian vertebrate, Jamoytius kerwoodi White. Palaeontology, 53:1393-1409.

SAnsom, R. S., S. E. GabBott, AND M. A. Purnell. 2010b. Non-random decay of chordate characters causes bias in fossil interpretation. Nature, 463:797-800.

SAnsom, R. S., S. E. Gabbott, And M. A. Purnell. 2011. Decay of vertebrate characters in hagfish and lamprey (Cyclostomata) and the implications for the vertebrate fossil record. Proceedings of the Royal Society of London B-Biological Sciences, 278:1150-1157.

Sansom, R. S., S. E. Gabbott, and M. A. Purnell. 
2013. Atlas of vertebrate decay: A visual and taphonomic guide to fossil interpretation. Palaeontology, 56:457-474.

SANSOM, R. S., AND M. A. WILlS. 2013. Fossilization causes organisms to appear erroneously primitive by distorting evolutionary trees. Scientific Reports, 3: 2545.

SKAWINA, A. 2010. Experimental decay of gills in freshwater bivalves as a key to understanding their preservation in Upper Triassic lacustrine deposits. PALAIOS, 25:215-220.

Vinther, J., D. E. G. Briggs, R. O. Prum, AND V. SARANATHAN. 2008. The colour of fossil feathers. Biological Letters, 4:522-525.

XIAO, S., AND A. H. KNOLl. 1999. Fossil preservation in the Neoproterozoic Doushantuo phosphorite Lagerstatte, South China. Lethaia, 32:219-240.

XiaO, S., AND M. Laflamme. 2009. On the eve of animal radiation: phylogeny, ecology and evolution of the Ediacara biota. Trends in Ecology \& Evolution, 24:31-40. 